sentences were employed to provide a verbal context for item pairs of individual items), but not in S1, S2, S3, or S4 (where one or a few sentences were employed to relate three or more of the list's items).

Looking back at the mean ranks in Table 3, one should note that in the S6,S12, and $\mathrm{SO}$ conditions there is a tendency for ranked TEPs to increase going across item transitions. With S1, S2, S3, and S4, however, there is no such increase in mean ranks. For $S 1$, the trend may be observed as first increasing and then decreasing, yielding the significant quadratic trend associated with it. For S2, S3, and S4, one is led to the conclusion that there are only chance deviations from the expected average rank of 6.00 .

It is possible that in the less organized conditions ( $\mathrm{S} 6, \mathrm{~S} 12$, and $\mathrm{S} 0$ ), serial learning under the recall method proceeded in kind of a rote, piecemeal fashion. That is, on the first few trials only the initial items of the list were acquired in their correct serial order, while scrambled bits and pieces from the rest of the list were tacked on as well. With increasing trials, these latter items became more correctly associated in serial order, and then added to the already mastered preceding chunks. Such performance would result in a small proportion of TEPs for early items in the list, and a larger proportion of these errors for items occurring later in the list, which is in accordance with the trend data presented.

Under the assumption that the well organized conditions ( $1, \mathrm{~S} 2, \mathrm{S3}$, and S4) provided various item links throughout the list, it might be predicted that for these conditions TEPs would be approximately equal at each item transition. Specifically, since at each transition in the list, there were connections provided by the preceding item or items, no dramatic increase in the number of conditional errors would be expected at the lattermost transitions. The absence of a linear trend in any of these better organized conditions provided empirical support.

\section{REFERENCES}

FRIEDMAN, M. The use of ranks to avoid the assumption of normality implicit in the analysis of variance. Joumal of the American Statistical Association, 1937, 32, 675-701.

JENSEN, A. $R$. Is the serial-position curve invariant? British Journal of Psychology, 1962, 53,159-166.

JOHNSON, N. F. The psychological reality of phrase-structure rules. Journal of Verbal Learning \& Verbal Behavior, 1965, 4, 469-475.

MARASCUILO, L. A., \& McSWEENEY, M. Nonparametric post hoc comparisons for trend. Psychological Bulletin, 1967, 67, 401-412.

MEDNICK, S. A. Learning. Englewood Cliffs, N.J.: Prentice-Hall, 1964.

MILLER, G. A., \& SELFRIDGE, J. A. Verbal context and the recall of meaningful material American Journal of Psychology, 1950, 63, 176-185.
SIMPSON, W. E. Effects of approximation to sentence word-order and grammatical class upon the serial learning of word lists. Journal of Verbal Learning \& Verbal Behavior, 1965, 4, 510-514.

SIMPSON, W. E. Errors versus correct responses in the serial learning of word lists. Psychonomic Science, 1967, 7, 213-214.

\section{NOTES}

1. This article is based on the author's thesis, submitted in partial fulfillment of the $\mathrm{PhD}$ degree at the University of California, Berkeley. The author wishes to acknowledge the financial support of the research by the Graduate Division of the University of California, and the inspiring guidance received from Dr. William D. Rohwer, Jr. The author is indebted to Dr. Donald Hardy and his staff at the Inland Valley Elementary School in Orinda, California, without whose support this study would not have been possible.

2. A more detailed description of the experimental materials and procedures may be obtained from the author upon request.

3. The method selected for analyzing serialposition errors is a potentially useful alternative to that recommended by Jensen (1962), in comparing serial-position curves from different conditions which are not equal with respect to task difficulty.

\title{
Natural language mediation and interitem interference in paired-associate learning'
}

JACK A. ADAMS, JOHN S. MCINTYRE, ${ }^{2}$ and HOWARD I. THORSHEIM, 3 University of Illinois, Urbana, Ill. 61801

The effects of interitem interference and natural language mediators (NLMs) on verbal performance were assessed by giving $200 \mathrm{Ss}$ eight trials on a list of 10 paired associates. The NLMs were recorded for each item, each trial. Mediated items had higher performance than rote items. The final items on a trial were subject to more interitem interference and were recalled less well than initial items, with no appreciable difference between rote and mediated items.

Recent studies (e.g., Tulving \& Arbuckle, 1963) demonstrated that interference among items of a verbal list is a potent influence on item recall. Adams \& Montague (1967) have shown that natural language mediators (NLMs), which are the idiosyncratic associative devices that Ss report they often use to learn paired associates, can reduce the amount of list interference in a RI design. In the present study the Adams-Montague findings are extended to the individual item, with the expectation that mediated items will show less interitem interference.

\section{PROCEDURE}

All Ss received eight trials on a list of 10 paired associates. The anticipation method was used with the $4: 4 \mathrm{sec}$ rate. There was no break between trials; the 80 items were presented continuously except for one brief apparatus delay discussed below.

Our procedure for an item was to have $S$ report the response term if he could when the stimulus term alone was showing, as is standard for the anticipation method. The next presentation was the stimulus and response terms of the pair together for knowledge of results and learning, and it was here that we asked $S$ to verbalize his le arning mode and speak his NLM aloud if he was using one or to say "Rote" if he was not. The $E$ did not record the NLM verbatim; he checked only whether the item was NLM or rote. Instructions explained mediated and rote learning without emphasizing either one. Three trials were given on a list of five neutral pairs for familiarization.

Ten different starting orders of the list were defined, and there was a different order of the 10 items on each subsequent trial. Furthermore, the logic gave a fixed sequence of $1,4,5,7,8,10,11,13,14$, and 17 items intervening between the two presentations of items on successive trials. The item which was in Position 9 on Trial $\mathbf{n}-1$ was always in Position 1 on Trial $n$ to give retroactive inhibition (RI) in Amount 1, the item in Position 7 on Trial $n-1$ was always in Position 2 on Trial $n$ for $\mathrm{RI}$ in Amount 4 etc. All items preceding the stimulus slide for a particular item exert a proactive inhibition (PI) effect, and over trials the items contributing to PI steadily increase, 
Table 1

Percentage of Items in Each Learning Mode, Whether Item was Correct or Incorrect

\begin{tabular}{|c|c|c|c|c|c|c|c|}
\hline & 2 & 3 & 4 & $\begin{array}{l}\text { Trial } \\
5\end{array}$ & 6 & 7 & 8 \\
\hline $\begin{array}{l}\text { Mediated } \\
\text { Rote } \\
\text { None }\end{array}$ & $\begin{array}{r}28.4 \\
66.3 \\
5.3\end{array}$ & $\begin{array}{r}28.9 \\
65.6 \\
5.5\end{array}$ & $\begin{array}{r}33.9 \\
62.9 \\
3.2\end{array}$ & $\begin{array}{r}37.3 \\
60.9 \\
1.8\end{array}$ & $\begin{array}{r}40.7 \\
57.9 \\
1.4\end{array}$ & $\begin{array}{r}43.1 \\
56.2 \\
0.7\end{array}$ & $\begin{array}{r}46.3 \\
53.2 \\
0.5\end{array}$ \\
\hline
\end{tabular}

but the RI was always in Amounts $1,4,5 \ldots$ 14,17 on successive trials. VERBAL MATERIALS

The pairs were chosen from 50 pairs used in a previous study (Adams \& McIntyre, 1967). No two pairs had a stimulus letter the same. The pairs were: WW-46, MM-26, AA-42, B-37, J-39, QQ-28, TT-19, H-36, C.38, and Y.22.

\section{APPARATUS}

A Carousel projector was used along with Hunter Interval Timers for timing the 4:4 rate. The projector required $1 \mathrm{sec}$ to change slides, so the timer was set for $3 \mathrm{sec}$ in order for the time between successive slides to be $4 \mathrm{sec}$. Because of evidence that $S$ uses all of the time available to him for the associative process (Cooper \& Pantle, 1967), all of the time between slides was counted including change time. Two slides were required for a pair, and so the 80 items required 160 slides, which meant that two slide magazines were required. The changing of magazines produced a brief interruption after Trial 4, which E kept minimal.

\section{SUBJECTS}

The group had 200 university students as Ss who were paid for their participation. Both men and women were used. Twenty Ss were randomly assigned to each of the 10 starting orders of the list.

\section{RESULTS}

\section{Mediation vs Rote Learning}

Table 1 gives the percentage of items that were mediated and rote on all trials after the first informing trial. Items for which $S$ reported no specific mode of learning before the slide changed are in the None category and, being relatively few, were omitted from the data plotted in Fig. 1. Table 1 shows that the percentage of mediated responses regularly increases with trials while rotes steadily decrease.

Ignoring the solid diagonal lines in Fig. 1 for the moment, and attending only to the dashed curves of trial means for rote and mediated items, it can be seen that mediated items have an impressive advantage over rotes. The mean superiority for all trials combined is $28 \%$.

\section{Item Forgetting}

An item in a list has PI and RI confounded and disallows uncontaminated plots of PI and $\mathrm{RI}$ effects separately, but the compound of PI and RI influences to show low and high amounts of interference can be meaningfully represented. The arrangements of items on each trial was such that the first two items had the least amount of RI and, being initial items, had fewest preceding items and the least PI. Similarly, the last two items had the most RI and the most PI. Figure 1 has the means of the first two and last two items on each trial joined by the solid diagonal line. The item forgetting from the beginning to the end of a trial was positively related to the amount of interference, being as much as $20 \%$ in one case (rote items, Trial 6) and usually in the vicinity of $10 \%$. The amount of forgetting differed little for rote and mediated items or level of practice.

\section{DISCUSSION}

Caution must be used in an interference explanation of the short-term item forgetting which Fig. I shows as a source of variability in paired-associate learning. The poorer recall of items at the end of a trial had more time passing since their presentation on the previous trial as well as more intervening items and $\mathrm{RI}$, so the trace decay and interference explanations are confounded. This confounding is common in studies of short-term forgetting of items within a list.

The effects of the practice variable and NLMs on item forgetting produce other cautions for interference theory. Short-term retention is known to increase with amount of practice (e.g., Hellyer, 1962) and a resistance to interference is known to develop as the degree of learning increases

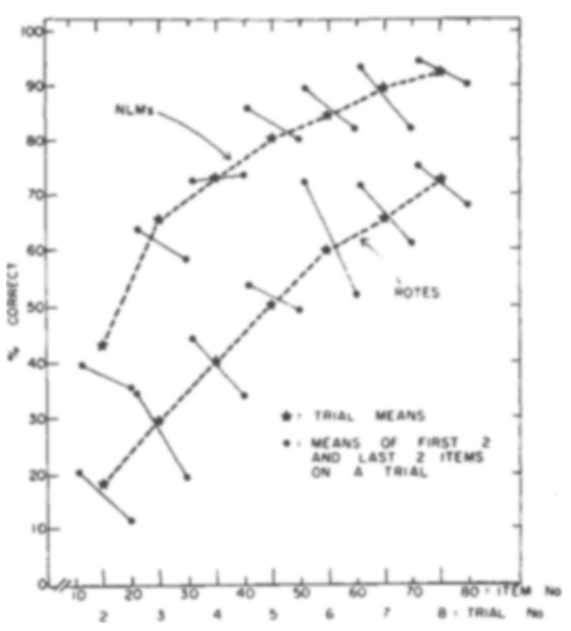

Fig. 1. The dotted lines are the learning curves for rote and mediated items. The solid line is the retention loss from the first two to the last two items on a trial.
(Adams, 1967, Chap. 4), but Fig. 1 shows that the greater forgetting for late items on a trial does not decrease with trials. Keller et al (1967) obtained the same finding. Moreover, the greater forgetting for late items is about the same for mediated and rote items, which is inconsistent with the findings of Adams \& Montague (1967) that NLMs reduce interference. The superiority of mediated over rote performance in Fig. 1 is an established finding by now, and it would seem to reflect a transfer of associative strength from past language learning rather than a reduction in interitem interference.

The percentage of mediated and rote items (Table 1) had a trend different from Adams \& McIntyre's (1967). They found percentage of mediated items to first increase and then decrease with trials, but the present study found mediated items to steadily increase. There are two likely explanations. First, Adams \& McIntyre (1967) had a higher terminal level of performance in their data, and the gradual dropping out of mediators may depend on it. Second, Adams and McIntyre had self-paced recall but here we paced the recall at 4 sec. Pacing is temporally demanding, and would produce some failures because time was insufficient for responses with latencies longer than $4 \mathrm{sec}$. In the presence of this failure $S$ might shift toward a mediation strategy which leads to greater success. Pacing is ordinarily thought to affect only the opportunity to respond, which is obviously true, but less obvious is that pacing might alter the type of behavior.

\section{REFERENCES}

ADAMS, J. A. Human memory. New York: McGraw-Hill, 1967.

ADAMS, J. A., \& McINTYRE, J. S. Natural language mediation and all-or-none learning. Canadian Journal of Psychology, 1967, 21 , 436-449.

ADAMS, J. A., \& MONTAGUE, W. E. Retroactive inhibition and natural language mediation. Journal of Verbal Learning \& Verbal Behavior, 1967,6, 528-535.

COOPER, E. H., \& PANTLE, A. J. The total-time hypothesis in verbal learning. Psychological Bulletin, 1967, 68, 221-234.

HELLYER, S. Supplementary report: Frequency of stimulus presentation and short-term decrement in recall. Journal of Experimental Psychology, 1962, 64, 650.

KELLER, L., THOMSON, W. J., TWEEDY, J. R. \& ATKINSON, R. C. Effects of reinforcement intervals in paired-associate learning. Joumal of Experimental Psychology, 1967, 73, 268-277.

TULVING, E., \& ARBUCKLE, T. Y. Sources of intertrial interference in immediate recall of paired associates. Joumal of Verbal Learning \& Verbd Behavior, 1963, 1, 321-334. NOTES

1. This research was supported by Grant No. US PH MH-12022 from the U.S. Public Health Service. Sara W. Smith and Thomas O. Nelson assisted in the experiment.

2. Now at the University of Manitoba, Winnipeg, Canada.

3. Now at St. Olaf College, Northfield, Minn. 